\title{
Memory Effects on Saudi Arabian Stock Market - Empirical Evidence
}

Dr. Khalid Alkhathlan, Asst. Professor,

Department of Economics,

King Saud University, Riyadh,

Kingdom of Saudi Arabia (KSA)

P.O BOX : 165, Kharj - 11942

Kingdom of Saudi Arabia (KSA)

Contact. No.: 0966-1-467-4178,

E-mail:- kaa8161@hotmail.com

S Prabakaran, Asst. Professor,

Department Finance,

College of Business Administration, AL - Khraj

King Saud University,

P.O BOX : 165, Kharj - 11942

Kingdom of Saudi Arabia (KSA)

Contact. No.: 00966-504697489,

E-mail:- joprabapdf@gmail.com 


\begin{abstract}
s
This paper makes a serious endeavor to investigate whether there exists a need to study the use of non-linear models to test the survival of memory effects in a developing stock market like Saudi Arabia, performing thereon the various statistical tests for the normality of data. It also discussing how various authors are challenging the efficient market hypothesis. This has led to the use of non-linear dynamic systems for modeling movement in stock prices. In order to confirm whether the efficient market hypothesis is applicable to the Saudi Arabian Stock Market, the study has used the TADAWUL returns for the last two decade and tested them for normality. And also find out the various features of the logarithmic return spectrum of the Saudi Arabian stock markets. It also scrutinizes the possible existence of dependencies and memory effects in the return processes. In particular, it performs Rescaled Range (R/S) analysis. The results throw up several intriguing issues of relevance to portfolio managers, stock market players and analysts and academicians.
\end{abstract}

Key Words: EMH, Chaos, Brownian Motion, R/S method, TASI 


\section{Introduction}

The pioneering work in adapting statistical methods to the analysis of stock market behaviour and return patterns is credited to the French mathematician Louis Bachelier (Bachelier, 1964), who applied the formal tenets of probabilistic calculus to study the price movements of stocks, bonds, futures, and options in the relevant trading marketplaces (stock exchanges/commodities exchanges etc.). Bachelier's paper (Bachelier, 1964), in retrospection, was a work of incredible foresight, many years ahead of its time. It completely revolutionized the study of finance, paving the way for the origin of a distinct branch of study called "quantitative finance". In fact, not only this, another far reaching implication of Batchlier's work was the recognition that the random walk process (later formalized by Weiner) (Weiner, 1976) is Brownian motion. Einstein rediscovered this result several years later (Einstein, 1908).

Bachelier's thesis was, undoubtedly, revolutionary, but received little attention for several decades. During the decades of the 1920s through the 1940s, market analysis was dominated by fundamental analysts (followers of Graham and Dodd) and technical analysts. It was only in the 1950s that the quantitative analysts (followers of Bachelier) became active and came to the fore.

Little work was done in the application of statistical analysis to study stock market behavior until the late 1940s. However, thereafter, progress was rapid. Cootner compiled his classic volume The "Random Character of Stock Market Prices" (Cootner, P. ed. ,1964), published in 1964 which strongly facilitated the progression of quantitative analysis.

Cootner's work (Cootner, P. ed. ,1964) lays down the premises for the development of the "Efficient Market Hypothesis" that was formally propounded by Fama (Fama, 1970 and 1965) in the 1960s.

\section{Efficient Market Hypothesis}

Fama (Fama, 1970 and 1965) in 1965 formalized the work of Osborne into the Efficient Market Hypothesis (EMH), which states, in technical terms, that the market is a martingale, or "fair game"; that is, information cannot be used to profit in the marketplace.

The theory of "efficient markets." constitutes the bedrock of quantitative capital market theory, and in the last four decades, research in capital market has depended on it. One of the important consequences of the EMH is that it justifies the use of probability calculus in analyzing capital markets.

In this context, it is pertinent to mention that if the stock prices show nonlinear characteristics, then the use of standard statistical analysis can give misleading results, particularly if a random walk model is used.

The cardinal philosophy of EMH is that all assets are priced so that all public information, both fundamental and price history, is already discounted in the prevailing market prices. Prices, therefore, move only when new information or/and new events is received. One cannot outperform an efficient market by gaming because 
not only do the prices reflect known information, but the large number of in vestors will ensure that the prices are fair. Investors are considered rational in efficient markets so that they know, in a collective sense, what information is important and what is not. After digesting the information and assessing the risks involved, the collective consciousness of the market finds an equilibrium price. Essentially, the EMH says that the market is made up of too many people to be wrong.

If the aforesaid assumption is true, then today's change in price is caused only by today's unexpected surprise. Yesterday's news is no longer important, and today's return is unrelated to yesterday's return; the returns are independent. If returns are independent, then they are random variables and follow a random walk. If enough independent price changes are collected, in the limit (as the number of observations approaches infinity), the probability distribution becomes the normal distribution. This assumption regarding the normality of returns enables a large spectrum of statistical tools, tests and modeling techniques to be adopted for studying price behaviour of assets. This is the random walk version of the EMH.

It must, however, be emphasized here that, technically, market efficiency does not necessarily imply a random walk, but a random walk does imply market efficiency. Therefore, the assumption that returns are normally distributed is not necessarily implied by efficient markets. But all the same, the EMH in any version says that past information does not affect market activity, once the information is generally known. This independence assumption between market moves naturally lends itself first to a random walk theory, and then to more general martingale and submartingale models.

The concept of efficient markets gradually got rooted into capital market theory and went on contradict fundamental analysis as well as technical analysis. In the initial stages, EMH propounded that past price information was not related to future prices. However, in 1973 Lorie and Hamilton (Lorie and Hamilton 1973) remarked that.

The assertion that a market is efficient is vastly stronger than the assertion that successive changes in stock prices are independent of each other. The latter assertion- "the weak form" of the "efficient market hypothesis"-merely says that current prices of stocks fully reflect all that is implied by the historical sequence of prices so that a knowledge of that sequence is of no value in forming expectations about future prices. The assertion that the market is efficient implies that current prices reflect and impound not only all of the implications of the historical sequence of prices, but also all that is knowable about the companies whose stocks are being traded it suggests the fruitlessness of efforts to earn superior rates of return by the analysis of all public information."

This attack on fundamental analysis was not well received by a significant investment community, and the EMH was split into the "weak" and "strong" forms (Vega, 1991). The strong form suggested that fundamental analysis was a useless activity, because prices already reflected "all that is knowable," or all public and private (insider) information whereas the weak form postulated that prices reflect only past price histories.

As a compromise, the "semistrong" form was articulated (Bagarello, 2007). In the 
semistrong version of the EMH, prices reflect all "public" information. Security analysts, using Graham-and-Dodd techniques (Graham, 1959), formulate value based on information that is available to all investors. A large number of independent estimates results, in. a "fair" value by the aggregate market. Analysts, thus, become the reason for making markets efficient. Fundamental analysts form a fair price by consensus.

The semistrong form of the EMH was much more acceptable to the investment community because it said that markets were efficient because of security analysis, not in spite of it. In addition, the semistrong form implied that changes in stock prices were random because of influences outside the price series itself. That is, price changes were random because of the evaluation of the changing fundamentals of a company, caused by both micro- and macro-economics. By the mid-1970s, the semistrong version of the EMH was the generally accepted theory.

In conclusion, semistrong version of EMH claims that markets are efficient because prices reflect all public information. A weak - form efficient market is one in which the price changes are independent and may be a random walk.

\section{Chaos (Beran, 1994; Campbell, et al, 1997) \& Stock Markets}

Chaos, as a physical phenomenon, has attained recognition relatively recently. Its origin, in its modern form, may be traced to the revolutionizing work of the master French mathematician Henri Poincare in the 1890s', on the mathematical aspects of planetary motion, treating it as a three-body problem. Through the use of topological methods, he established that there is no simple solution to the three-body problem. During the course of his analysis, he realized that if one takes two different readings on the position of a planet, then, irrespective of the proximity of the two readings, the orbits of the planets might separate away from each other, after enough time. Hence, accurate prediction of the orbit of any planetary body was impossible. Chaos was, thus, born.

Chaos provides a link between deterministic systems and random processes. In a deterministic system, chaotic dynamics can amplify small differences, which in the long run produce effectively unpredictable behavior. On the other hand, it is possible that not all random-looking behavior is the product of complicated interactions and hence, may well be tractable in the deterministic framework. The existences of non-linearities in only a few degrees of freedom are sufficient to generate chaotic motion. In such cases, it is possible to model the system behavior deterministically and to make short-term predictions that are far better than those that would be obtained from a linear stochastic model. Chaos is thus a double-edged sword: it implies that even approximate long-term predictions may be impossible, but that very accurate short-term predictions may be possible. Hence, chaos has both good and bad implications for the prediction problem.

Decision making of all kinds, including investments in the capital markets, rests on our ability to predict the future. However, business and, indeed, life in general, is not predictable. Conventionally, in decision theory, this lack of predictability is explained by factors such as lack of information or the limitations of prediction techniques. 


\section{Macrothink}

Chaos theory, however, provides a radically opposite explanation, in that it accepts unpredictability as an inherent attribute of a wide range of phenomena, so that, forecasting may be an entirely futile and wasteful exercise.

Prediction and forecasting have, hitherto, relied essentially on various linear models like regression, linear programming, and capital budgeting and so on. It is, however, now established beyond doubt that all fundamental processes of Nature have various degrees of non-linearity. In fact, Chaos is a manifestation of the non-linearities inherent in a system in so far as such unpredictable phenomena are forbidden in linear systems by the very virtue of their linearity.

A corollary to this ubiquitous non-linearity is the high degree of approximation incumbent in all the contemporary decision making processes. Chaos theory emphasizes that because of this sensitivity to initial conditions, many events simply cannot be predicted, because it would be impossible to know and monitor all the variations that might have a significant effect on the outcomes.

A compact, concise and universally acceptable definition of Chaos has, hitherto, eluded the scientific community. However, the following are conventionally accepted as the inherent characteristics of a chaotic system:-

- Exponential divergence of neighboring trajectories in phase space;

- Sensitive dependence on initial conditions;

- Existence of fractal dimensions;

- Critical levels and bifurcations at which the system's behavior radically changes;

- Time dependent feedback.

As had happened in the case of Edward Lorenz, chaotic systems are highly sensitive to initial conditions insofar as minor differences tend to get magnified manifold with the evolution of the system. This is illustrated in the Henon Map, figure $1 \& 2$ defined by the following set of simultaneous difference equations:-

$$
\begin{aligned}
& x_{(t+1)}=1+y_{t}-a x_{t}^{2} \\
& y_{(t+1)}=b x_{t}
\end{aligned}
$$




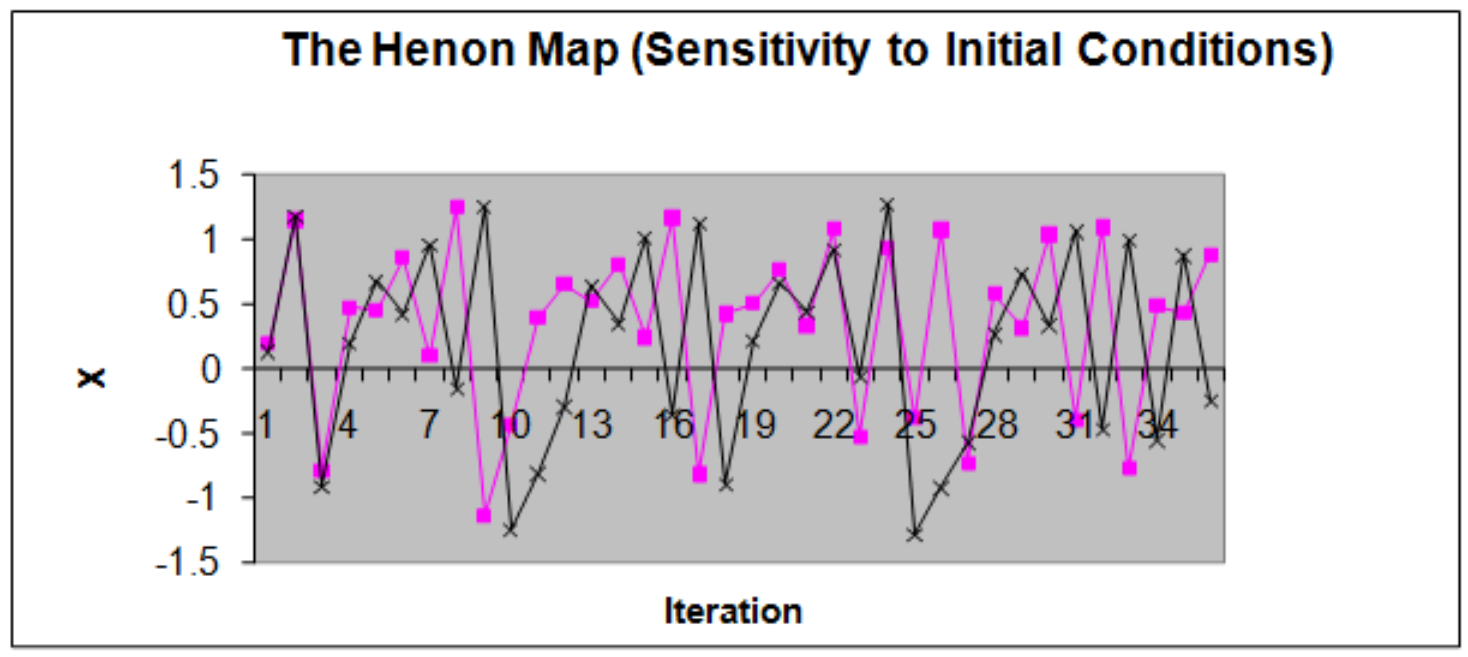

Figure 1

from above fig explain that the origin of this sensitive dependence may be attributed to the existence of time dependent feedback mechanisms, the implications are devastating. Unpredictability becomes an inherent attribute and long term forecasting becomes a futile exercise. Marginally small errors in data collection would manifest themselves magnified manifold in forecasted output. For all we know, even with the best available measurement devices, error free measurement is impossible, a fundamental lower limit being imposed by Heisenberg's Uncertainty Principle.

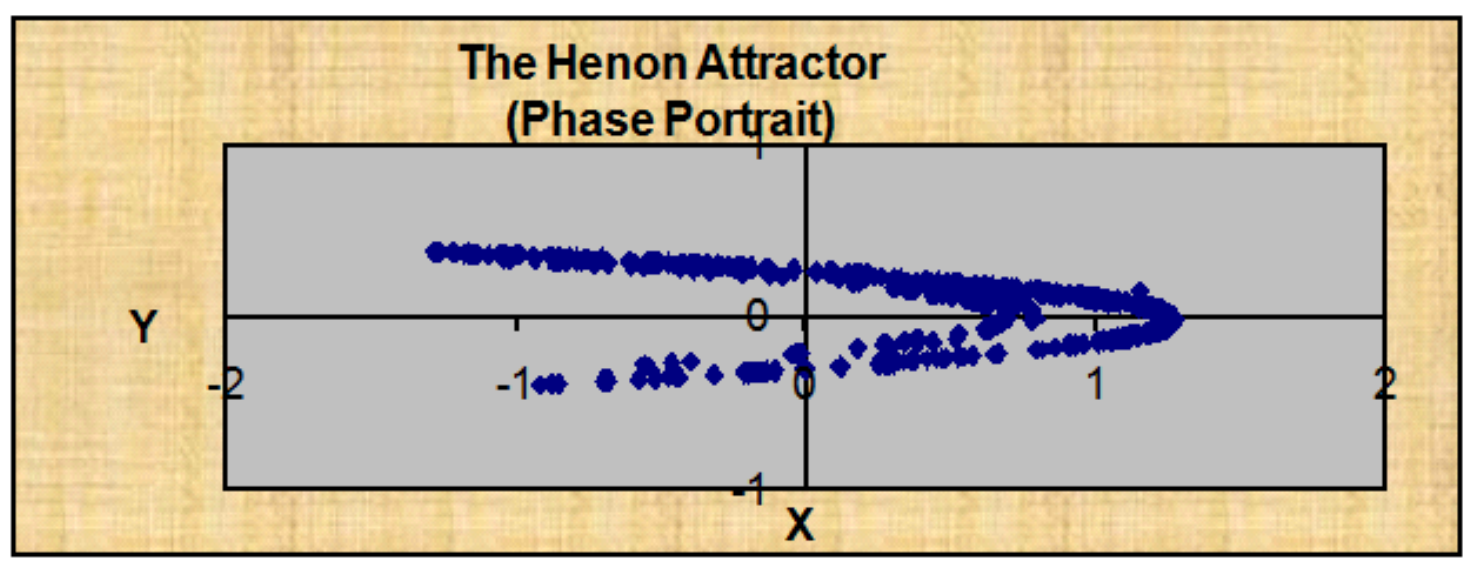

Figure 2

Chaos theory propounds the adoption of a radically new perspective to forecasting. It emphasises the need to acknowledge the true dimensions of uncertainty in its absoluteness and to discard the conventional and traditional so called "rationalistic" models like the Efficient Market Hypothesis. Chaos theory recognises the existence of disorder, discontinuities and randomness as inherent properties or norms rather than as 
aberrations. Consequent to the acceptance of unpredictability as an inherent property, chaos theory tends to dwell heavily on the necessity of development of adequate "fire fighting" mechanisms as an indispensable part of planning and forecasting.

Several studies (Baxter M. and Rennie, E. 1992; Mantegna, 1991) adopting largely diverse and independent approaches have established the existence of the following characteristics in the behavior of stock markets:-

- Long term correlation and memory effects

- Occasional existence of erratic markets

- Existence of fractal dimensions in stock market time series of returns

- Less reliable forecasts with increase in the horizon thereby establishing the probable existence of chaotic behavior of stock markets.

As mentioned above, the phenomenon of chaos is a manifestation of the non-linearities intrinsic to the dynamic equations of motion that govern the time development of a system.

\section{Objective of the Study}

Saudi joint stock companies had their beginning in the mid 1930's, when the "Arab Automobile" company was established as the first joint stock company. By 1975 there were about 14 public companies. The rapid economic expansion, besides the Saudisation of part of the foreign banks capital in the 1970's led to the establishment of a number of large corporations and joint stock banks.

The market remained informal, until the early 1980's when the government embarked on forming a regulated market for trading with the required systems. In 1984, a Ministerial Committee composed of the Ministry of Finance and National Economy, Ministry of Commerce and Saudi Arabian Monetary Agency (SAMA) was formed to regulate and develop the market. SAMA was the government body charged with regulating and monitoring market activities until the Capital Market Authority (CMA) was established in July 2003 under the Capital Market Law (CML) by Royal Decree No. $(\mathrm{M} / 30)$. The CMA is the sole regulator and supervisor of the capital market, it issues the required rules and regulation to protect investors and ensure fairness and efficiency in the market.

Experts on financial markets and economists on both Random Walk and Efficient Market Hypothesis have undertaken good amount of research work. However, long memory models are relatively new to applied economics. Though its origin dates back to (Mandelbrot and Wallis, 1969) work, it was not until 1980's that researchers began to apply the rescaled range analysis, one of the tools in the long memory theory, to financial markets and macroeconomic prices. In 1991 Lo modified the classical R/S method, (Beran, 1994) a stationary process with long memory has the following qualitative features: 


\section{Mll Macrothink}

- Certain persistence exists. In some periods the observations tend to stay at high levels, in some other periods, the observations tend to stay at low levels.

- During short time periods, there seem to be periodic cycles, however looking through the whole process; no apparent periodic cycles could be identified.

- Overall, the process looks stationary.

The primary objective of this study is to investigate if the price behavior in Saudi Arabian stock market can be characterized by long memory models. It is not hard to find evidence to argue that price series with random appearance might be non-linear dynamic. But it is difficult to say what kind of non-linear dynamics. Another commonly used stochastic model ARCH and its variants share similar symptoms with long memory models, such as non-normality and heteroscedasticity, but they have totally different generating mechanisms and implications. A time series with ARCH property typically has two components, a conditional mean and a conditional variance function. The non-linearity of the series comes from the non-linearity of the conditional variance. An ARCH model that fits the data well could improve the prediction of the variances of prices but not the price itself (Bera and Higgins 1995). A long memory model is a single mean equation (system) and has a flexible structure. It represents short as well as long memory simultaneously.

Literature available depicts studies concerning developed and emerging markets, though major work has been undertaken for developed market like US. The unavailability of reliable data may one of the important reasons why very few studies have been undertaken in emerging markets. For Saudi financial market very few studies have tested long memory component.

The potential presence of stochastic long memory in financial asset returns has been an important subject of both theoretical and empirical research. If assets display long memory, or long-term dependence, they exhibit significant autocorrelation between observations widely separated in time. Since the series realizations are not independent over time, realizations from the remote past can help predict future returns. Persistence in share returns has a special claim on the attention of investors because any predictable trend in returns should be readily exploitable by an appropriate strategy by the market participants.

The financial markets (Abraham A, et al. 2002) in the Gulf region are dominated by commercial banks. Stock markets are relatively small in terms of markets capitalization, listed companies are few, most securities are infrequently traded, and trading volume is low. In addition, access to the Gulf markets for direct investment in equities, until recently, was only permitted to its nationals, with limited access to nationals from others states in the Gulf Cooperation Council (GCC). Increasing capital requirement to fund budget deficits and economic development has encouraged the regional states to launch capital market liberalization and broad - ranging structure reforms, allowing foreign 
investors greater access to the financial markets. In recognition of the growing importance of these markets, the IFC (International Financial Corporation) has recently included the equity indices of Bahrain and Saudi Arabia in its emerging market database.

The Saudi stock market, with 111 listed companies, is the largest stock market based on value of shares traded by sectors (1633.6 Billion Riyals up to September 2008) in the Gulf region. Trading in shares takes places over the counter through banks and is facilitated by an electronic trading system. Compared to the emerging markets, the overall shares turnover ratio is low. Accessibility to foreign investors is very restrictive. Only recently, non - Saudi investors have been allowed to invest indirectly through the purchase of mutual fund shares. Saudi Arabia allows only GCC nationals to own a limited number of shares and in a limited number of shares and in number of companies. With respects to other markets, only India imposes some restrictions on foreign ownership which is currently limited to $24 \%$ of stock of listed companies.

\section{Empirical Studies on Stock Market Prices}

Before the EMH was even fully formed, exceptions to the normality assumption were being found. When, in 1964, Osborne (Osborne, 1964) plotted the density function of stock market returns, he found them only to be "approximately normal" with extra observations in the tails of the distribution (kurtosis). The tails were fatter than they should be.

The existence of "fat tails" was almost universally acknowledged by 1964 but the implications of this departure from normality were widely debated. Mandelbrot's chapter in the Cootner volume (Cootner, 1964) suggested that returns may belong to a family of "Stable Paretian" distributions, which are characterized by undefined or infinite variance. Cootner contested the suggestion, which would have seriously weakened the Gaussian hypothesis, and offered an alternative in which sums of normal distributions may result in a distribution that looks fat-tailed but is still Gaussian.

In 1965, in an extensive study, Fama (Fama, 1965) observed that returns were negatively skewed: more observations were in the left-hand (negative) tail than in the right-hand tail, the tails were fatter and the peak around the mean was higher than predicted by the normal distribution. This statistical condition is called "leptokurtosis."

In 1970, Sharpe (Sharpe, 1964) compared annual returns to the normal distribution, and found that extremal values of stock returns occurred much more often that that predicted by the normal distribution.

E. Peters (Wiley 1996) in 1990 performed an extensive study of volatility, using daily S\&P index returns from 1928 through 1990. They also obtained similar results. Table 1 summarizes their findings. They found that "daily return distributions for the Dow Jones and S\&P 500 are negatively skewed and contain a larger frequency of returns around the mean interspersed with infrequent very large or very small returns as 


\section{Macrothink}

compared to a normal distributions."

A graph of the frequency distribution of returns of the 5-day logarithmic first difference in prices for the S\&P 500 from January 1928 to December 1989 is presented in Figure 3 (a) as adapted from the above study E. Peters (Wiley 1996). The returns have been normalized so that they have a zero mean and a standard deviation of one. A frequency distribution for an equal number of Gaussian random numbers is also shown. The high peak and fat tails can be clearly seen. In addition, the return data have a number of four- and five-sigma events in both tails. Figure 3 (b) illustrates the differences between the two curves. The negative skewness can be seen at the count three standard deviations below the mean. The stock market's probability of a three-sigma event is roughly twice that of the Gaussian random numbers.
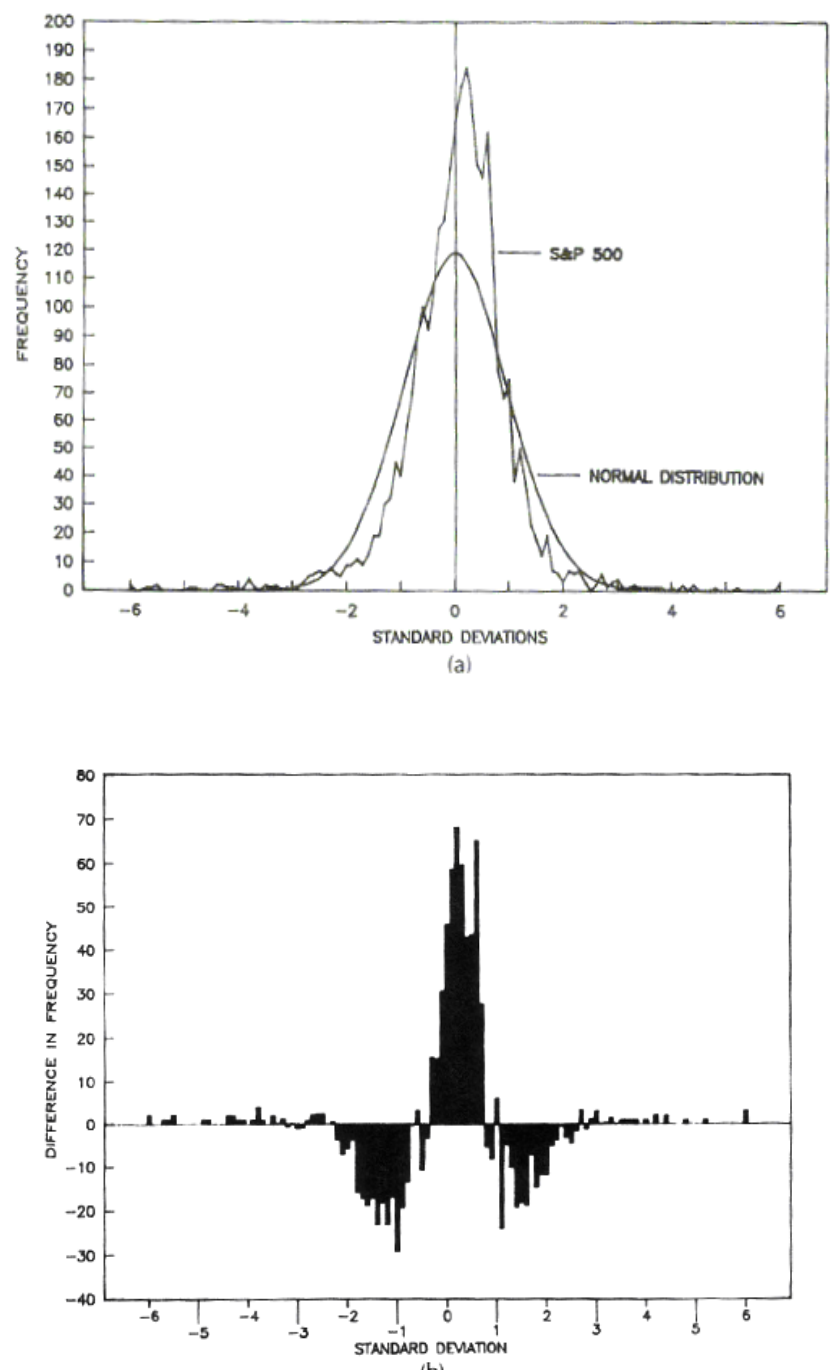

Figue 3

A more explicit representation of the above features can be seen in Table 1 which is also adapted from the same study E. Peters (Wiley 1996). 
Table 1 Volatility Study: Daily S\&P 500 Returns, 1/28-12/89

\begin{tabular}{|c|c|c|c|c|}
\hline Decade & Mean & $\begin{array}{c}\text { Standard } \\
\text { Deviation }\end{array}$ & Skewness & Kurtosis \\
\hline $1920 \mathrm{~s}$ & 0.0322 & 1.6460 & -1.4117 & 18.9700 \\
\hline $1930 \mathrm{~s}$ & -0.0232 & 1.9150 & 0.1783 & 3.7710 \\
\hline $1940 \mathrm{~s}$ & 0.0100 & 0.8898 & -0.9354 & 10.8001 \\
\hline $1950 \mathrm{~s}$ & 0.0490 & 0.7050 & -0.8398 & 7.8594 \\
\hline $1960 \mathrm{~s}$ & 0.0172 & 0.6251 & -0.4751 & 9.8719 \\
\hline $1970 \mathrm{~s}$ & 0.0062 & 0.8652 & 0.2565 & 2.2935 \\
\hline $1980 \mathrm{~s}$ & 0.0468 & 1.0989 & -3.7752 & 79.6573 \\
\hline Overall & 0.0170 & 1.1516 & -0.6338 & 21.3122 \\
\hline
\end{tabular}

Adapted from E. Peters (Wiley 1996)

In another recent study of quarterly S\&P 500 returns, from 1946 through 1988, Friedman and Laibson (Friedman and Laibson, 1989) point out that "in addition to being leptokurtotic, large movements have more often been crashes than rallies" and significant leptokurtosis "appears regardless of the period chosen."

Sterge (Sterge, 1969), in a study of financial futures prices of Treasury Bond, Treasury Note, and Eurodollar contracts, found the same leptokurtotic distributions. Sterge notes that "very large (three or more standard deviations from the norm) price changes can be expected to occur two to three times as often as predicted by normality."

These studies offer ample evidence that U.S. stock market returns are not normally distributed. If stock returns are not normally distributed, then much statistical analysis, particularly diagnostics such as correlation coefficients and t-statistics (Levin et al, 1997), is seriously weakened and may give misleading results. The case for a random walk in stock prices is also seriously weakened.

It is pertinent to mention that tests of normality have also been conducted in several stock markets of other countries including the United Kingdom (Meric et al, 2007), Japan (Nagayama et al, 2006), Hong Kong (Man, 2006) \& India (Matia, 2004).

Tests on normality of stock prices have also be attempted from a different perspective viz. the scaling of volatility or standard deviation. The variance is stable and finite for the normal distribution alone. In fact, if the capital markets fall into the "Stable Paretian" family of distributions, as postulated by Mandelbrot, they would have infinite variance.

Studies of volatility have tended to focus on stability over time. In the normal distribution, the variance of $n-d a y$ returns should be $n$ times the daily return i.e. the variance scales in proportion to time. This constitutes a useful test for the normality of the underlying data. This scaling feature of the normal distribution is referred to as the $T^{1 / 2}$ Rule, where $T$ is the increment of time.

The investment community often "annualizes" risk, using the $T^{1 / 2}$ Rule. Annual 
returns are usually reported, but volatility is calculated based on monthly returns. The monthly standard deviation is therefore converted to an annual number by multiplying it by the square root of 12 -a perfectly acceptable method, if the distribution is normally distributed.

Studies show that standard deviation does not scale according to the $T^{1 / 2}$ Rule. Turner and Weigel (Turner and Weigel, 1990) found that monthly and quarterly volatility were higher than it should be, compared to annual volatility but daily volatility was lower than it should be.

Studies of volatility have also been conducted using the autoregressive conditional heteroskedastic (ARCH) model of Engle (Engle, 1982). This model sees volatility as conditional upon its previous level. Thus high volatility levels are followed by more high volatility, while low volatility is followed by more low volatility. This is consistent with Mandelbrot's observation (Mandelbrot, 1964) that the size of price changes (ignoring the sign) seems to be correlated. Statistical evidence compiled by Engle and LeBaron (Leboran, 1990) among others supports the ARCH model. In recent years this has led to increasing recognition that standard deviation is not a standard measure, at least over the short term. ARCH also results in fat tailed probability distributions. Therefore, ARCH has had the most impact upon option pricing and technical trading rules.

In addition, there have been numerous market anomalies in which excess nonmarket returns has be achieved, contrary to the "fair game" of the semi-strong EMH. In the stock market, these include the small firm effect (Stoll and Whaley, 1983), the low P/E effect, and the January effect. Rudd and Clasing (Stoll et al, 1983) document excess returns realized from nonmarket-factor returns generated by the BARRA El six-factor risk model. This CAPM (Fabozziet al, 2006) - based model found that four sources of nonmarket risk (market variability, low valuation and unsuccessful, immaturity and smallness, and financial risk) all offered the opportunity for significant nonmarket returns. Rudd and Clasing (Rudd and Clasing, 1982) say that these factor returns are "far from random," suggesting that the semistrong EMH is flawed. These anomalies have long suggested that the current paradigm requires an adjustment that takes these anomalies into account.

\section{Testing \& Evidence on the Normality of Stock Market Returns in Saudi Arabia}

As mentioned above, the pivotal fallout of the Efficient Market Hypothesis is that the present price of a security encompasses all the presently available information including past prices - concerning this security and prices tend to move only if and when new information about the security percolates into the market. Even the seminal work of Fischer Black \& Myron Scholes (Black and Scholes, 1973) in the pricing of contingent financial claims (that constitutes the cornerstone of contemporary valuation theory) presupposes that the stock prices follow a geometric Brownian motion, the two principal attributes whereof are that:-

(i) The set of stock prices $S(t), 0 \leq t<\infty$ constitute a geometric Brownian motion 
if, $\forall s, t \geq 0$, the random variable $\frac{S(s+t)}{S(t)}$ is independent of all prices up to time $t$;

(ii) $\ln \left[\frac{S(s+t)}{S(t)}\right]$ is a normally distributed random variable $\forall s, t \geq 0$ with mean $\mu t$ and variance $t \sigma^{2}$ where $\mu$ and $\sigma$ constitute the parameters defining the geometric Brownian motion.

(iii) It follows from (i) \& (ii) that the probabilities of the ratio of the price at time $s$ in the future to the present price will not depend on the present price. Additionally, if $\mu$ and $\sigma$ are known, then it is only the present price - and not the history of past prices - that affects the expectations of future prices. Specifically, we have, $E[S(t)]=S(0) e^{\left(\mu+\frac{1}{2} \sigma^{2}\right) t}$.

In the empirical study that constitutes the substratum of this paper, we test the hypothesis that future price movements are independent of past movements i.e. the stock market logarithmic returns follow a normal distribution in the Saudi capital markets. We also examine whether memory effects of any significant duration subsist in these markets. We assume the TADAWUL market index as the proxy for the Saudi stock market and conduct the analysis of the TADAWUL All Share Index (TASI) over the period from January 07, 2007 to December 14, 2008 consisting of 485 observations. A chronological plot of the TASI values for the above period is given in Figure 4.

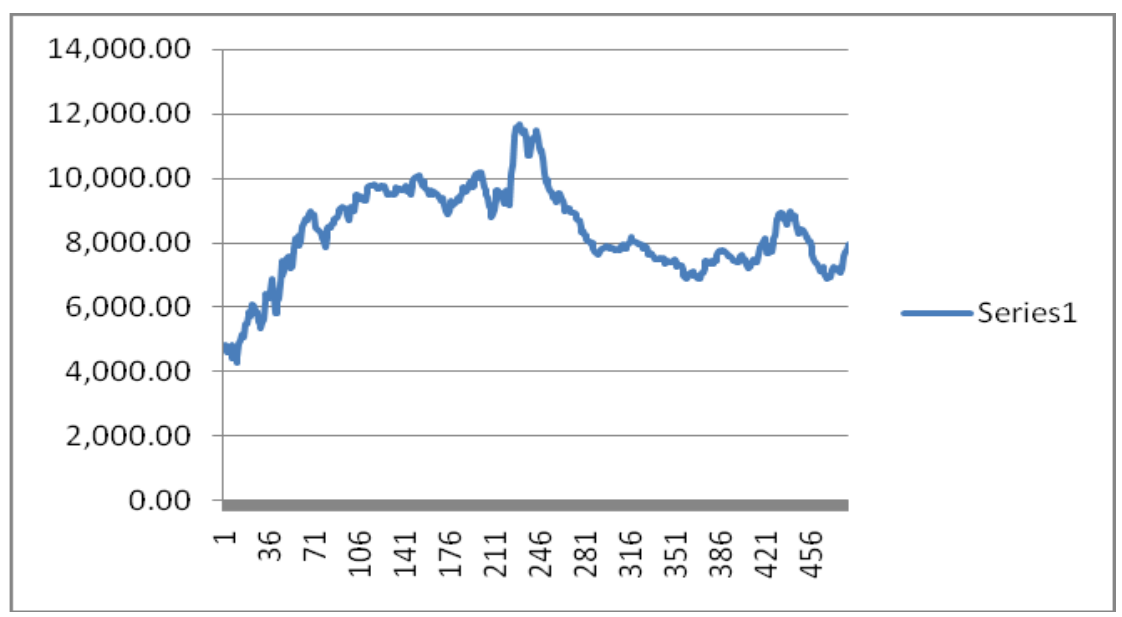

Figure 4

The mean and standard deviation of the daily logarithmic returns of the prices constituting the sample was found to be -0.00105 and 0.02164 respectively. To test these returns for normality, the number and percentage of observations in the various $0.5 \sigma$ intervals were calculated and compared with the corresponding values for the 
standard normal distribution $\mathrm{N}(0,1)$. The results are tabulated in Table 2 below:-

\begin{tabular}{|l|c|c|}
\hline Interval & No of Observation & \% of Total \\
\hline$x \leq \bar{x}-2 \sigma$ & 16 & 0.03299 \\
\hline $\bar{x}-2 \sigma<x \leq \bar{x}-1.5 \sigma$ & 13 & 0.026804 \\
\hline $\bar{x}-1.5 \sigma<x \leq \bar{x}-\sigma$ & 21 & 0.043299 \\
\hline $\bar{x}-\sigma<x \leq \bar{x}-0.5 \sigma$ & 48 & 0.098969 \\
\hline $\bar{x}-0.5 \sigma<x \leq \bar{x}$ & 114 & 0.235052 \\
\hline $\bar{x}<x \leq \bar{x}+0.5 \sigma$ & 153 & 0.315464 \\
\hline $\bar{x}+0.5 \sigma<x \leq \bar{x}+\sigma$ & 78 & 0.160825 \\
\hline $\bar{x}+\sigma<x \leq \bar{x}+1.5 \sigma$ & 28 & 0.057732 \\
\hline $\bar{x}+1.5 \sigma<x \leq \bar{x}+2 \sigma$ & 3 & 0.006186 \\
\hline $\bar{x}+2 \sigma<x$ & 11 & 0.02268 \\
\hline
\end{tabular}

Table 2

The following fig 5 shows that the log normal distribution for the daily logarithmic returns of the prices index.

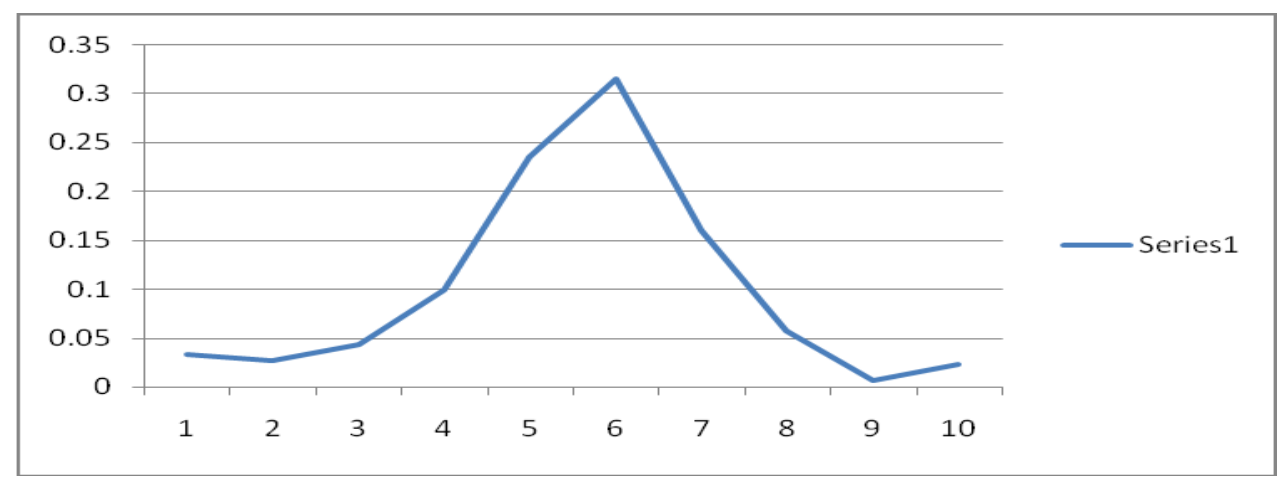

Figure 5

A histogram corresponding to the above data is placed at Figure 6. It is clear from the histogram that the assumption of normality of log-returns is, at best, questionable. 


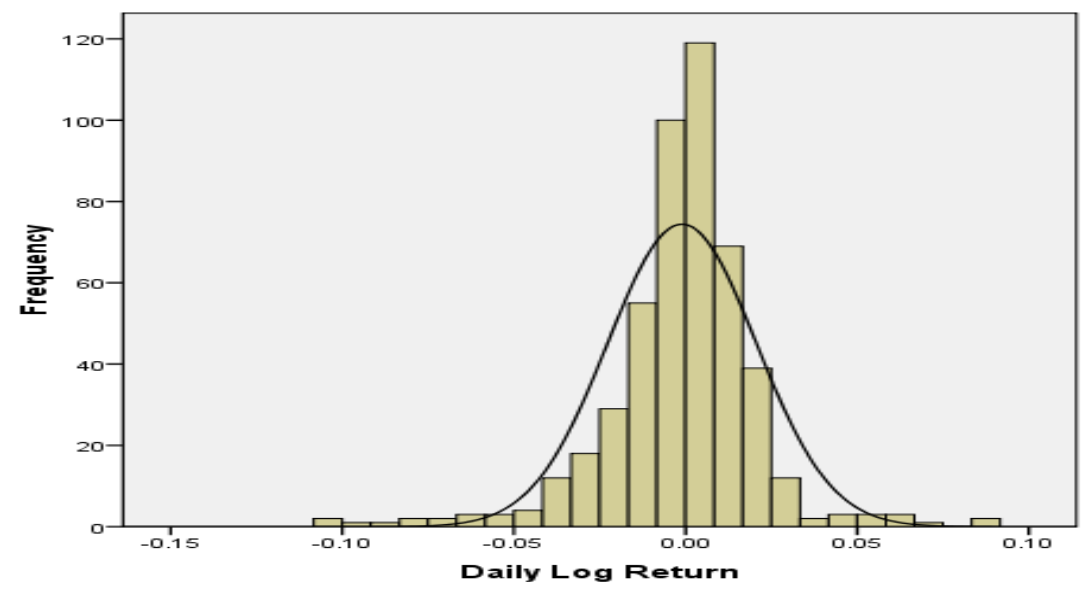

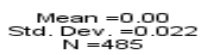

Figure 6

While analyzing the TASI returns data for the period from January 2007 to December 2008 , it was found that the tails were a bit fatter, and more significantly the peak around the mean was higher than predicated by the normal distribution. This can be seen from the above figure $\mathrm{X}$. The daily returns were normalized so that they have a mean of zero and standard deviation of one. The most common explanation of the fat tails is that information shows up in frequent clumps, Rather than in a smooth and continues fashion. We can seen from the above that the daily returns are negative skewed for TASI and contain a large frequency of returns around the mean.

The following table 3 summarizes the findings for TASI:

\begin{tabular}{|l|l|l|l|}
\hline Average & Std Deviation & Skewness & Kurtosis \\
\hline-0.00105 & 0.02164 & -0.70711 & 5.128611 \\
\hline
\end{tabular}

Table 3

Now we will discuss how the trends indicate the persistence of long memory in TASI. There are two important methodologies we can use.

a. Persistence Tests

b. Variance Test Ratios.

\section{Persistence Tests}

If the stock price gives you an idea about long memory, or long - term confidence, they show signs of significant autocorrelation between observations extensively not speaking in time. This involves what occurred not only in recent past but long time back has a comportment on the today's market prices and hence continuation of an autocorrelation between these observations. Today's risk inhibition policies followed in Saudi securities market is constructing on the basis of historical price behavior. Since the series comprehensions are not independent over time, comprehensions from the remote past 
can help us envisage future movement in stock prices. Persistence in share returns has a special claim on the consideration of investors because any unsurprising trend in returns should be readily utilizable by suitable strategy.

Contemporary empirical research have tested long memory hypothesis for the behavior of stock market price /return patterns. The paper (Black and Scholes, 1973) used Hurts Rescaled Range (R/S) analyzed and he accomplished that capital market prices do not reflect information immediately, as the efficient market hypothesis take for granted, but rather follow a biased random walk that replicates persistence. Another study (Green and Fielitz, 1977) also using the rescaled range (R/S) and they accounted evidence of persistence in daily U.S. Stock returns series. Many authors did their research work into stock market overreaction has also uncovered evidence that a measure of predictability can be identified previous position in stock returns. Specifically, shares of companies, which have performed well in the past subsequently, perform less well in the future, while shares, which have performed badly in the past usually, improve their performance (MacDonald and Power, 1992). Some of the authors concluded that the classical $\mathrm{R} / \mathrm{S}$ test is prejudiced in the direction of finding long - term memory too repeatedly. Stock market returns possibly will tag along biased time paths that standard statistical tests cannot differentiate from random behavior. Rescaled range analysis is used to become aware of long - term, non periodic cycles in stock market returns. If this modus operandi is not correctly, however, then it can be predisposed by short - term biases, most important to the flawed wrapping up that the stock market has long - term memory.

Another research (Lo, 1991) developed a modified R/S method, which taken in hand some of the negative aspects of the classical R/S method. By means of the variant of $\mathrm{R} / \mathrm{S}$ analysis, Lo finds no substantiation to sustain the incidence of long memory in U.S stock returns. Applying Lo test, this does not rely on normal regression techniques and is vigorous to short - term dependence, make available statistical prop up for the hypothesis that stock market returns follow a random walk (Ambrose, et al, 1993). Using both the modified R/S method and the spectral regression method, in the paper (Cheung and Lai, 1995) find no confirmation of persistence in several international stocks returns series. Another research (Crato, 1994) reports comparable evidence for the stock return series of $\mathrm{G}-7$ countries using exact maximum likelihood assessment. Basically these studies have been the stochastic long memory performance of stock returns in most important capital market. In disparity, the long memory deeds in smaller markets have conventional little attention.

Today, we see an unmanageable response to emerging from investors across the world. These markets have provided diversification opportunity to international investors. It must be noted that such markets are very expected to exhibit characteristics different from those observed in developed capital markets as the market micro - structure is different in emerging markets vis-a-vis developed ones. Biases due to market thinness and non-synchronous trading should be expected to be more severe in the case of the emerging markets.

In the paper, we gave the impression of being for substantiation of long memory in Saudi Stock markets. We have used data about return from the TADAWUL All Share 
Index (TASI) to check for persistence of long memory in daily returns data. The TASI data is actual closing values from January 2007 to December 2008 (485 observations). Two statistical methods have been used for test: (i) sample one T - Tests (ii) The Hurts Exponent (R/S analysis) to test the data. These two tests have been selected to find out if the same result or the result differs even if we use the same dataset.

\section{Sample one $\mathbf{T}$ - Tests}

To further corroborate the departure of real data from the geometric Brownian motion and the subsistence of significant memory effects we have also performed the sample one T-Tests to test the hypothesis that all the change in the daily price lag index data sets describe normal random variables having the following table with mean difference with $95 \%$ confidence interval of the difference. The results of the analysis are tabulated below in Table 4 (a) and (b):-

\section{a. One sample statistic}

\begin{tabular}{|c|c|c|c|}
\hline Time Lag & Mean & Std. Deviation & Std. Error Mean \\
\hline 15 & $7.2303 \mathrm{E} 3$ & 259.14970 & 66.91217 \\
\hline 30 & $7.3108 \mathrm{E} 3$ & 320.38189 & 58.49346 \\
\hline 90 & $7.7984 \mathrm{E} 3$ & 611.12729 & 64.41847 \\
\hline 180 & $7.6614 \mathrm{E} 3$ & 511.19962 & 38.10257 \\
\hline 270 & $8.2523 \mathrm{E} 3$ & 1194.89747 & 72.71914 \\
\hline 360 & $8.5869 \mathrm{E}$ & 1196.23375 & 63.04705 \\
\hline 485 & 8.3641 & 1424.98755 & 65.87007 \\
\hline
\end{tabular}

b. One sample Test

\begin{tabular}{|c|c|c|c|c|c|c|}
\hline \multicolumn{7}{|c|}{ Test Value $=0$} \\
\hline Time Lag & $t$ & $d f$ & Sig.(2-tailed) & $\begin{array}{c}\text { Mean } \\
\text { Difference }\end{array}$ & $\begin{array}{l}95 \% \text { C } \\
\text { Interv } \\
\text { Diff } \\
\\
\text { Lower } \\
\text { Upper }\end{array}$ & $\begin{array}{l}\text { nfidence } \\
\text { lof the } \\
\text { rence }\end{array}$ \\
\hline 15 & 108.057 & 14 & .000 & 7230.29600 & 7086.7837 & 7373.8083 \\
\hline 30 & 124.985 & 29 & .000 & 731.82000 & 7191.1874 & 7430.4526 \\
\hline
\end{tabular}




\begin{tabular}{|l|l|l|l|l|l|l|}
\hline 90 & 121.058 & 89 & .000 & 7798.35222 & 7670.3541 & 7926.3504 \\
\hline 180 & 201.073 & 179 & .000 & 7661.38150 & 7586.1935 & 7736.5695 \\
\hline 270 & 113.481 & 269 & .000 & 8252.26944 & 8109.0984 & 8395.4405 \\
\hline 360 & 136.198 & 359 & .000 & 8586.88917 & 8462.9012 & 8710.8771 \\
\hline 485 & 126.979 & 484 & .000 & 8364.12968 & 8234.6912 & 8493.5681 \\
\hline
\end{tabular}

The computations provide an $\mathrm{T}$-statistic value is implies that the differences in the means and std deviation of the different lag time period and it also explain the t-test $t$ value and $95 \%$ confidence intervals of the difference. The significant are statistical acceptability of the hypothesis that the subsets different lag period i.e 15, 30, 90, 180, $270,360,485$ days intervals.

\section{Rescaled Range Analysis}

Variance has been, traditionally, used in one guise or another as the statistical measure of risk. Variance measures the probability that an observation will be a certain distance from the average observation. The larger this number, the wider the dispersion. Wide dispersion would mean that there is a high probability of large swings in returns. The security is risky. However, the use of variance as a measure of risk inherently assumes that the underlying system is random. If the observations are correlated, then the usefulness of variance as a measure of risk is considerably weakened.

We illustrate our point by an example. We consider two possible series of stock market returns, say A \& B:-

\begin{tabular}{|c|c|c|}
\hline Observation & A & B \\
\hline 1 & 2 & 1 \\
\hline 2 & -1 & 2 \\
\hline 3 & -2 & 3 \\
\hline 4 & 2 & 4 \\
\hline 5 & -1 & 5 \\
\hline 6 & 2 & 6 \\
\hline Standard Deviation & 1.70 & 1.71 \\
\hline Fractal Dimension & 1.42 & 1.13 \\
\hline
\end{tabular}

Table 5

A is a trendless series while B has a clear trend. Both have almost the same standard deviation. The two stocks with virtually identical risk (as measured by the standard deviation) have vastly differing return characteristics. The obvious fallacy is that both series are not normally distributed, but then the same is the case with the stock markets. As mentioned above, numerous studies have shown the non random character of the stock market returns, thereby questioning the usefulness of variance as a 
comparative measure of risk.

In contrast, the fractal dimension clearly shows that $\mathrm{A}$ is more jagged than $\mathrm{B}$, and hence, more risky. As a corollary, the fractal dimension may, at least qualitatively, depict the risk profile of a stock more rationally than the standard deviation.

There is a simple mathematical link between the Fractal Dimension or the associated Hurst's Exponent $\mathrm{H}$ and the physical dimension. $\mathrm{H}=1$ corresponds to a perfectly persistent series representable by a unidimensional line whereas $\mathrm{H}=0.50$ corresponds to random or Brownian motion, it is equal to a dimension of 1.50, a fractal or noninteger dimension halfway between a line and a plane. And where $\mathrm{H}=0$, a perfectly antipersistent time series, the corresponding physical dimension is a plane or 2 .

\section{Conclusion}

The normality tests on the daily TADAWUL returns for the last one decade indicates the need to explore the application of non-linear modeling techniques in the Saudi Arabian Stock market. But we come to see that the results from the persistence tests are split in right side. From the above discussion need to be conducted to understand if the present risk containment system applicable in capital market margining is in line with the long memory of the capital market. If there is not enough proof to support long memory, then we can discard the path of historical volatility to use as margining principles and go for something else. We can observe that the index value is fall down from 16712.64 Billion to 7933.29 Billion (nearly 53\%) in 2005 to 2006 . This is one of the main drawbacks in the Saudi stock market. Because most of the main player takes back their money from the Saudi stock market. Some reforms have to be done to the Saudi Stock Market such as in order to maintain stability.

One of the main observations from this study is that the Saudi Stock Market is not predictable. This study proves that history of the market is no important when making the decision of investment in the market which is a drawback in the Saudi Stock Market. In order to attract foreign investment and local investor's wall as, some main reform has to be done regarding censor the market. The market has to adopt policies that attract long term investment to maintain stability in the market.

\section{References}

Abraham A, et al. (2002), "Testing the Random Walk Behavior and Efficiency of the Gulf Stock Markets" The Financial Review 37, pp 469-480, 2002;

Ambrose, B.W.; Ancel, E.W.; Griffiths, M.D. (1993), "Fractal Structure in the Capital Markets Revisited”, Financial Analyst Journal, May-June 1993;

Bachelier, B.C.(1964), "Theory of Speculation", in P. Cootner, ed., The Random Character of Stock Market Prices. Cambridge, M.A: MIT Press, 1964;

Bagarello, F. (2007), Physica A: Statistical Mechanics and its Applications, Volume 386, Issue 1, 1 (December 2007), pp 283-302;

Basu and Morey, (1998), Stock Market Prices in India after Economic Liberalization, EPW February 14, 1998; 
Baxter M. and Rennie, E. (1992), Financial Calculus, Cambridge University Press, (1992);

Bera, A and Higgins, M. (1995), "On ARCH Models, Properties, Estimation, and Testing” In Survey in Econometrics, ed L Oxley, D A R George, C J Roberts and S Sayer, Blackwell Press, Oxford of UK and Cambridge of USA, pp-171 - 215;

Beran, J. (1994), "Statistics for Long memory Process" Chapman and Hall Publishing;

Black, F.; Scholes, M. (1973), Journal of Political Economy, 81, (1973), 637;

Campbell, J.Y., A. W. Lo and A. C. MacKinlay, (1997), "The Econometrics of Financial Markets", Princeton University Press, Princeton, NJ;

Cheung, Y. and Lai, K. (1995), “A Search for Long Memory in International Stock Market Returns", Journal of International Money and Finance, 14, pp. 597-615;

Cootner, P. ed. (1964), The Random Character of Stock Market Prices. Cambridge: MIT Press, 1964; Crato, N. (1994), "Some International Evidence Regarding the Stochastic Behaviour of Stock Returns", Applied Financial Economics, 5, pp. 339-349;

Dacrrogna M.M. et al, (1993), J. Int'1 Money \& Finance, 12, (1993), 413;

Einstein, A.(1908), Annals of Physics 322, 1908;

Engle, E.R., Econometrics 50, (1982);

E. Peters, Chaos \& Order in the Capital Markets, second edition (Wiley 1996);

E. Peters, Fractal market analysis (Wiley 1994);

"Evidence Using High Frequency Data", Journal of Business Finance \& Accounting, 19(4), pp.505-514;

Fabozzi, Frank J.; Focardi, Sergio M.; Kolm, Petter N. (2006), Financial Modeling of the Equity Market: From CAPM to Cointegration, Wiley (2006);

Fama, E.F. (1965), Journal of Business 38, (1965);

Fama, E.F. (1970), Journal of Finance 25, (1970);

Fama, E.F. (1965), Management Science, 11, (1965);

Friedman, B.M. and Laibson, D.I. (1989), "Economics Implications of Extraordinary Movements in Stock Prices", Brookings Papers on Economics Activity 2, (1989);

Graham, B., (1959), The Intelligent Investors, A Book of Practical Counsel, 3rd ed., New York:

Harper \& Brother, 1959;

Green, M.T. and Fielitz, B.D. (1977), "Long Term Dependence in Common Stock Returns", Journal of Financial Economics, 4, pp. 339-349;

Hida, T. (1980), "Brownian motion", Springer (1980); Inc, New York;

LeBaron, B. (1990), - Some Relations Between Volatility and Serial Correlations in Stock Market Returns\|, Working Papers, (February 1990);

Levin, Richard I. and Rubin, David S. (1997), Statistics for Management, Prentice Hall; 7 edition (1997);

Lo, A.W. (1991), "Long Term Memory in Stock Market Prices”, Econometrica, 59, pp. 1279-1313;

Lorie, J.H. and Hamilton, M.T. (1973), The Stock Market: Theories and Evidence. Home wood, IL: Richard D. Irwin, (1973);

MacDonald, R. and Power, D. (1992), "Persistence in UK Stock Market Returns" Some Man, Ming and Li, Rui (2006), University of International Business \& Economics 


\section{MIMacrothink}

(2006);

Mandelbrot, B. (1964), "The Variation of Certain Speculative Prices”, in P. Cootner, ed., Random Character of Stock Prices. Cambridge: MIT Press, 1964;

Mandelbrot, B., Wallis (1969), - Robustness of the Rescaled Range R/S in the measurement of Noncyclic Long Run Statistical Dependence - Water Resources Research 5, 1969;

Mantegna R.N., Stanley, H.E. (1996), Nature, 383, (1996), 587 Mantegna, R.N. (1991), Physica A, 179, (1991), 232;

Matia, K. et.al, (2004), Europhys. Lett., 66 (6), (2004), pp 909-914;

Meric, Gulser et, al, (2007), Middle east finance and economics, Issue I, (2007), pp 60-73;

Nagasawa, M. (2000), Stochastic Processes in Quantum Physics, Birkhauser, 2000;

Nagayama, Shohei and Takeda, Fumiko (2006), Presented at Asian-Pacific economic Association 2006 annual meeting;

Osborne, M.F.M. (1964), "Brownian Motion in the Stock Maraket", in P. Cootner, ed., The Random Character of Stock Market Prices. Cambridge: MIT Press, 1964;

Peters, E E. (1989), Fractal Structure in the Capital Markets, Financial Analysts Journal, July - August, pp 32 - 37;

Ross, S.M. (1999), Stochastic Processes, John Wiley, 1999;

Rudd, A. and Classing, H.K. (1982), Modern Portfolio Theory. Homewood, IL: Dow Jones -Irwin, (1982);

Sharpe, W.F.(1964), Journal of Finance 19, (1964);

Sterge, A.J. (1989), Financial Analysts Journal, (May/June 1989);

Stoll, Hans R. and Whaley, Robert E. (1983), Journal of Financial Economics Volume 12, Issue 1, (June 1983), pp 57-79;

Turner, A. L. and Weigel, E.J. (1990), “An Analysis of Stock Market Volatility”, Russell Research Commentaries, Frank Russell Company, Tacoma, WA, 1990;

Turner, A. L. and Weigel, E.J. (1990b), -An Analysis of Stock Market Volatilityll, Russell Research Commentaries, Frank Russell Company, Tacoma, WA, 1990;

Vega, T.(1991), Financial Analysts Journal, December/January, 1991;

Weiner, N. (1976), Collected Works, Vol. I, P.Masani ed. Cambridge: MIT Press, 1976. 